\title{
An Empirical Link of Content and Construct Validity Evidence
}

\author{
Craig W. Deville \\ Sylvan Prometric
}

\begin{abstract}
Since the 1940 s, measurement specialists have called for an empirical validation technique that combines content- and construct-related evidence. This study investigated the value of such a technique. A self-assessment instrument designed to cover four traditional foreign language skills was administered to 1,404 college-level foreign language students. Four subject-matter experts were asked to provide item dissimilarity judgments, using whatever criteria they thought appropriate. The data from the students and the experis were examined separately using multidimensional scaling followed by cluster and discriminant analyses. Results showed that the structure of the data underlying both the student and expert scaling solutions corresponded closely to that specified in the instrument blueprint. In addition, using canonical correlation, a comparison of the two scaling solutions revealed a high degree of similarity in the two solutions. Index terms: canonical correlation, construct validity, content validity, item dissimilarities data, multidimensional scaling.
\end{abstract}

\section{Theoretical Radkground}

Valididy

Some researchers have maintained that evidence of content validity can be sufficient to establish the validity of test scores (Yalow \& Popham, 1983). Ebel (1977) went so far as to say that "content validity is the only basic foundation for any kind of validity" (p. 59). Others have argued that content validity is not at all a form of validity (Fitzpatrick, 1983; Guion, 1977; Messick, 1975; Tenopyr, 1977). These critics of content validity have based their arguments on the reasoning that "one validates, not a test, but an interpretation of data..." (Cronbach,

APPLIED PSYCHOLOGICAL MEASUREMENT

Vol. 20, No. 2, June 1996, pp 127-139

(C) Copyright 1996 Applied Psychological Measurement Inc. 0146-6216/96/020127-13\$1.90
1971, p. 447). Cronbach's statement implies that validation efforts should focus on test scores. Messick (1975) saw the need to link the two approaches and stated that "content considerations may be appropriately brought under the purview of validity by linking them to responses" (p. 961). Accomplishing this convergent link between content and construct information provides a stronger argument for a unified approach to evidential validity (Messick, 1989b).

In addition to these arguments regarding the soundness of content validity, several writers have lamented the fact that few established procedures exist for collecting content-related evidence (Fitzpatrick, 1983; Guion, 1977; Osterlind, 1989). Thorndike (1982) pointed out that little work has been done by psychometricians to develop quantitative indexes or procedures for establishing the congruence between test content and curricular objectives. He stated that "test evaluators have generally been satisfied with making a subjective and qualitative evaluation of the congruence ... and expressing their evaluation in narrative form..." (p. 185).

Thorndike was indirectly calling for what others (Culliksen, 1950; Messick, 1975; Tenopyr, 1977) had already suggested, namely an empirical technique that would link data from ratings provided by subject-matter experts (SMEs) with data from actual responses to a test/instrument. Such a technique would link content and construct evidence. Available empirical techniques for establishing content validity (see Crocker, Miller, \& Franks, 1989) typically consider SME ratings as an infallible criterion, and provide a somewhat simplistic summary index of agreement between SME ratings and a given 
test blueprint. What is needed, however, is a more stringent, informative, and precise technique that provides an indication of the extent of congruence between content ratings from SMES and actual item response data.

To better understand if "...the expert has given us the correct criterion and the best method of measuring it" (p. 511), Gulliksen (1950) suggested factor analyzing SME ratings as a validation technique. Because expert judgment is fallible, Gulliksen (1950) saw the need to compare test results (i.e., responses) to the criterion of the SME judgments. The issue was voiced most cogently by Messick (1989a):

The way out of this bind is to evaluate (and inform) expert judgment on the basis of other evidence about the structure of the behavioral domain under scrutiny as well as about the structure of the responses. This other evidence, in actuality, is construct-related evidence. (p. 7)

Tucker (1961) performed a factor analysis (FA) on the intercorrelations of data obtained from $17 \mathrm{SMES}$ in order to "...investigate for systematic differences in value opinions regarding the proper content of such a test" (p. 580). It must be emphasized that the judges were directed as to the criterion to use when rating the items-namely, item relevance-and were also cautioned not to use other item criteria. Tucker's analysis resulted in two factors, the first interpreted as general approval of the items, and the second as a factor revealing differences of opinions between two groups of raters. Tucker stated that the methodology can "...indicate those cases when high general content validity is possible as well as to indicate the existence and nature of ambiguity and controversy relevant to the content validity of a test" (p. 585). The FA, however, essentially distinguished between two groupings of raters-one indicating rater agreement, the other indicating rater disagreement. The focus was on the raters and did not directly address the issue of item similarities or differences. In addition, and more importantly in the context of the present study, Tucker's work did not address the issue of the structure of the responses as required by Messick (1989a, see above).

The preference for FA is perhaps the main rea- son why there has not been an empirical comparison between SME item ratings and item responses. $\mathrm{FA}$, with a focus on items, would require too many raters to render this methodology practical. Because multidimensional scaling (MDS) requires far fewer SMEs, it is an excellent alternative.

Sireci (1995) and Sireci \& Geisinger $(1992,1995)$ introduced a technique using MDS to analyze the structure of items as perceived by SMEs. Their technique used MDS along with cluster analysis to compare the item similarity judgments provided by SMES to the grouping of the items as specified in the test blueprint. As these authors pointed out, the technique presented a strategy for analyzing "content representativeness" (Fitzpatrick, 1983), but because response data were not used, they limited the discussion to content, and not construct, validation.

Unique in the Sireci \& Geisinger (1992) study was that the SMES were required to provide the item similarity judgments through a "blind" procedure. Three SMEs were asked to rate the similarity of a 30-item Study Skills test on a Likert scale of 1 to 5. The items had been randomly ordered, and the judges were not given any criteria by which to rate the items that might bias their input. The judges' ratings were subjected to an individual differences analysis using the ALSCAL program (Young \& Harris, 1990), followed by a cluster analysis of the stimulus coordinates (Arabie, Carroll, \& DeSarbo, 1987; Kruskal \& Wish, 1978). The results indicated that the three SMEs, without prior knowledge of the test specifications, grouped the 30 items together quite similarly to the categories specified in the test blueprint. In other words, the underlying structure of the items as perceived by SMES matched that given in the test blueprint.

Sireci \& Geisinger (1992) stated that "...studies of content validation [including theirs] rarely employ test score data" (p. 17). For this reason, these authors refrained from discussing construct validity and conceded that the exclusion of test response data was a limitation of their study. In discussing implications for further research, they recommended an extension of their work using a confirmatory approach in order to investigate the correspondence between content structure as found in SME judgments and that 
found in actual test response data.

\section{Sell-Assessment}

Self-ratings have long been used in such fields as psychology and business (Reilly \& Warech, 1991), but have gained acceptance in foreign language education only in recent years (Oskarsson, 1989). Selfassessment (SA) has been used in foreign language programs for placement purposes in the United States and Canada with excellent success (Heilenman, 1991; LeBlanc \& Painchaud, 1985). These two studies specified SA items according to four skills (discussed below). Proponents of SA claim numerous advantages to its use relative to more conventional tests (Heilenman, 1990; von Elek, 1985).

Several language testing studies have examined the underlying structure of SA ratings using exploratory FA or a multitrait-multimethod approach (Bachman \& Palmer, 1981, 1982; Brütsch, 1979; Davidson \& Henning, 1985). Bachman \& Palmer (1981, 1982) demonstrated that $S A$ ratings exhibited a large amount of method variance, a finding consistent with studies of SAs in the applied psychology literature (Williams, Cote, \& Buckley, 1989).

The study presented here built on previous work, but primarily used a nonmetric data reduction technique-MDS- to analyze the underlying structure of student responses to foreign language SA items. In addition, following suggestions put forth in the measurement literature on validity since 1950 , this same empirical technique was used to analyze information provided by content area experts regarding the content representativeness of the items.

\section{Purpose and Objectives}

The SA instrument used here was constructed with two integrated objectives. The primary purpose was to use the results to facilitate the placement of incoming students into appropriate foreign language courses at a large midwestern university. SA was being considered as a potential complement to the standardized placement procedure already in practice. Results corresponding to this first objective are not reported here. Birckbichler, Corl, \& Deville (1993) present evidence of the utility of SA in the present context.
The second purpose of the present study was to determine the feasibility and value of a new technique in examining content- and construct-related evidence. Specifically, the objective was to assess the correspondence among several sources of data related to the instrument: information from test specifications, item dissimilarity judgments from SMEs, and examinee scores. Such convergent evidence would provide an internal validity check on the "descriptive assumption" (borrowing liberally from Kane, 1994, p. 435), which in this context refers to the specified structure underlying the SA items. In turn, this descriptive evidence would support the "policy assumption" (Kane, 1994, p. 435) mentioned in the first objective (i.e., the appropriateness and effectiveness of SA in placing students into required foreign language courses).

Validity is established so that meaningful and appropriate inferences and/or decisions about a construct can be made from test scores given the assessment purpose (Kane, 1994; Messick, 1989b; Moss, 1995; Shepard, 1993). The construct is operationally defined by test constructors when they develop blueprints, write items, and have items judged by SMEs. Test responses should also reflect the construct through empirical evidence indicating agreement or fit with the defined construct (Cronbach \& Meehl, 1955).

The present study sought to establish an empirical link between the defined construct, data from SMEs, and test response data. The technique provides a stronger argument for validity because it requires convergence among measures-measures from different points of view (test constructor, students, and SMES), and from different analytic techniques (paired comparisons and Likert ratings).

\section{Data And Ansis}

\section{Selr Assessments}

SA was operationally defined as the subjective ratings provided by students to items that describe a situation in which they would have to use the target language (e.g.g "I can write a term paper on a

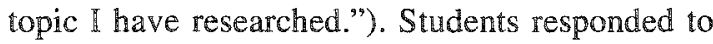
the statements using a five-category Likert scale indexing their perceived facility at accomplishing 
the language task, where 1 indicated hardly at all and 5 quite easily. In other words, a novice language learner would be expected to respond to the above statement about writing a term paper with a low number, but more advanced learners could be expected to rate their ability higher.

The SA approach used was a paper-and-pencil instrument consisting of 32 items and was based on previous work by Barrows et al. (1981). The content of the items reflected a balance among the four skills in foreign language learning: speaking, listening, reading, and writing. A balanced four skills approach was selected in order to correspond with the university curriculum into which students would be placed. Conventional summated scores (Likert, 1974; Spector, 1992), MDS (Napior, 1972), and additional analyses were then applied. MDS, as opposed to FA, was used on the student data in order to empirically compare the student solution with that from the SMES, for which FA was not an option. Using MDS on both datasets permitted a comparison of solutions based on the same data reduction model.

The sample consisted of 1,449 students enrolled in the beginning language course sequence at a large midwestern university in the three largest language departments: Spanish, French, and German. The student's ability level was operationally defined according to the language course in which the student was enrolled at the university, and into which incoming students would be placed. Students were drawn from three course levels.

\section{SMR Paired Comparisons}

Four SMEs, all Ph.D.s in foreign/second language education with extensive teaching and research experience, provided the item paired comparisons. According to Osterlind (1989), four is an acceptable number of SMEs for providing content ratings; Sireci \& Geisinger (1992) used three SMES to introduce their content validation technique (see below).

The 32 items yielded 496 item pairs, which were Ross-ordered (Ross, 1934). Ross ordering balances for "space" effects (i.e., the method balances the presentation of a given stimulus so that it appears evenly as the first and second member in the stimulus pairs) and "time" effects (i.e., the given stimu- lus is evenly spaced throughout the list of pairs) (Davison, 1992). The stimulus pairs were presented to the SMES on a nine-point scale, in which 1 meant the raters perceived the items to be very similar and 9 indicated that they were very dissimilar. No information regarding the test blueprint was given to the SMES; they were instructed to use whatever criteria they deemed important in providing their dissimilarity ratings.

\section{Analysis}

The ALSCAL MDS procedure was performed on both the student and SME data, followed by a hierarchical cluster analysis of the stimulus coordinates from both solutions. There were a total of 1,404 usable observations from the student data (i.e., observations without any missing values). These data were submitted to the PROXIMITIES procedure within SPSS- $X$ in order to obtain a matrix of Euclidean distance proximities among the 32 items. The Euclidean distance between two items is the square root of the sum of the squared distances between the item values:

$\operatorname{distance}(x, y)=\left[\sum_{j}\left(x_{j}-y_{j}\right)^{2}\right]^{1 / 2}$,

where $x_{j}$ and $y_{j}$ are the Likert values assigned by student $j$ to items $x$ and $y$. The proximities were then run using ALSCAL and two-to five-dimensional nonmetric solutions were examined to determine the most appropriate solution. The raters' item dissimilarity judgments were also input into ALSCAL and nonmetric two- to five-dimensional solutions were obtained. Two related fit measures, STRESS and RSQ, were used as statistical criteria to evaluate the solutions (Young \& Harris, 1990).

A useful approach for determining neighborhoods in an MDS solution is to apply cluster analysis to the stimulus coordinates. Ward's method (Aldenderfer \& Blashfield, 1984) was used on the item coordinates, because of its use in the literature (Olman, Stricker, \& Barrows, 1990; Sireci \& Geisinger, 1992) and because of its demonstrated ability to recover structure (Milligan \& Cooper, 1987). In addition, discriminant analysis was used to predict group mem- 
bership of the items from the stimulus solution to determine how well the values from the stimulus coordinates would classify the 32 SA items with respect to the original test specifications. Canonical correlation then was used to examine the congruence between the SME and student data.

\section{虫esullits}

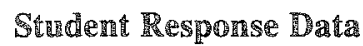

MDS analysis. Table 1 shows the STRESS and RSQ values from ALSCAL for each solution for the SA data. In addition to the STRESS and RSQ values, the plots of the solutions were also examined in order to determine which solution afforded the best interpretation of the data.

\section{Table 1}

ALSCAL STRESS and RSQ Values Obtained

From Two- to Five-Dimensional Nonmetric Solutions on Student and SME Data

\begin{tabular}{lcccr}
\hline \multicolumn{5}{c}{ Solutions on Student and SME Data } \\
\cline { 2 - 5 } Dataset & \multicolumn{4}{c}{ Dimension } \\
and Index & 2 & 3 & 4 & 5 \\
\hline Student Data & & & & \\
STRESS & .13 & .08 & .06 & .05 \\
RSQ & .94 & .97 & .98 & .99 \\
SME Data & & & & \\
STRESS & .20 & .14 & .09 & .08 \\
RSQ & .82 & .88 & .93 & .94 \\
\hline
\end{tabular}

The five-dimensional solution was eliminated because the last dimension accounted for very little additional variance and could not be interpreted. The two-dimensional solution was also eliminated from consideration because the three- and four-dimensional solutions added interpretable dimensions.

The STRESS and RSQ values in Table 1 indicate that not much was gained statistically by adding a fourth dimension. This fourth dimension, however, was somewhat interpretable (see below). In addition, when an individual differences scaling model was run on the data, the results clearly showed that the more advanced students were using this fourth dimension. For these reasons, four dimensions were retained for further analysis (for the student data, these were Dimensions $\$ 1, \$ 2, \$ 3$, and \$4).

Figure 1 shows plots of two stimulus configurations derived from the student data. Figure la is a plot of Dimensions SI and S4, the dimensions that were the easiest and most difficult to interpret. Dimension 1 has several items located at the extremes of the dimension. Items 29 and 4 had high negative values, and Item 31 had a high positive value. Item 29 ("Write a term paper on a topic I have researched") had the highest negative value and was the language task perceived to be the most difficult by the students. Item 31 ("Write a few sentences describing a room in my house or apartment") had the highest positive value and was perceived to be the easiest language task. These coordinate values correspond to the Likert-scale means. Dimension $\$ 1$, therefore, was interpreted as perceived difficulty and indicated the challenge students attached to the language task. In order to confirm this interpretation, the coordinate values from Dimension $\$ 1$ were correlated with the item means, resulting in a virtually identical relationship $(r=.997)$.

The finding of a dimension corresponding to item difficulty may seem to contradict previous work by Davison (1985) and Davison \& Srichantra (1988), which demonstrated how MDS analyses, in contrast to FA, typically result in solutions in which a general item difficulty dimension has been removed. The work by Davison and his colleagues, however, was specific to MDS analyses in which correlations were used as proximities, not Euclidean distances as in the present study.

Dimension S1 was the only dimension for which distance along the dimension was meaningful. The distance of the items along the other three dimensions was not unambiguously interpretable. These other dimensions served to separate different clusters of items in space, sometimes called neighborhoods or regions (Kruskal \& Wish, 1978).

Dimension $\$ 4$ did not provide much variability (Figure 1a). Items 1 and 15 somewhat separated themselves from the others. Item 1 ("Tell what I plan to be doing 5 years from now") and Item 15 ("Understand a native speaker telling me about his/her family") are language tasks that provide very little structure to the students and allow them fexibility in their response.

耳tems 2 ("Give accurate, detailed directions explaining how to get to my house") and 17 ("Read and follow a cooking recipe") were located in an 
Figure 1

Stimulus Configurations of the Four-Dimensional Solution From the Student Data

a. Item Numbers for Dimensions S1 and S4

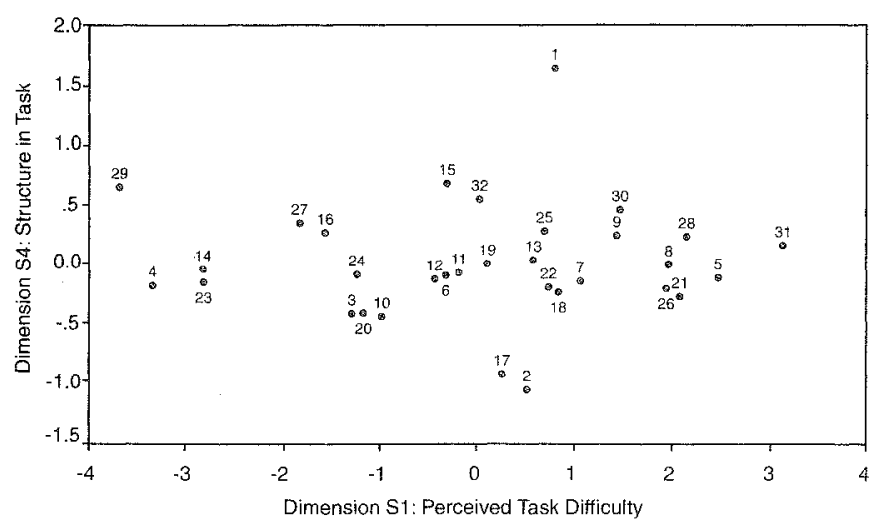

b. Item Classifications for Dimensions \$2 and S3

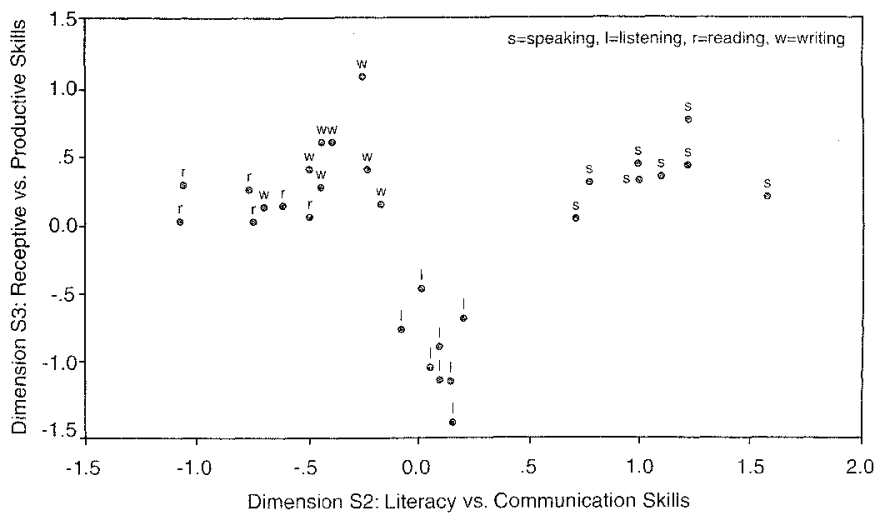

area beneath the other items. These items were much more structured and allowed the students little leeway in their responses. It may be that the more advanced students, who used this dimension to a greater extent than the novice learners, distinguished the items according to the range of freedom or creativity they perceived as inherent in accomplishing the language task.

The configuration obtained from ALSCAL and seen in Figure $1 b$ does not contain fixed axes. The configuration can be rotated to facilitate interpretation as long as the distance is maintained. When the configuration in Figure $1 \mathrm{~b}$ is rotated slightly to the left, the result displays a clear demarcation between the communication skills of speaking ( $\mathrm{s}$ ) and listening (1) and the literacy skills of reading (r) and writing (w). Whereas Dimension 52 can be interpreted as distinguishing between the communication and the literacy skills, Dimension $\$ 3$ was interpreted as disringuishing between the productive skills of speaking and writing versus the receptive skills of listening and reading. Dimension $\$ 3$ clearly separated speaking from listening. The separation between writing and reading was less clear, although the writing items were located in a region higher along Dimension S3.

Cluster and discriminant analyses. Using the 
information from the four-dimensional MDS solution, both the cluster analysis and the predictive discriminant analysis classified 31 of the 32 items according to the original test specifications. Only Item 25 was classified into another category than specified. This item ["Complete a simple questionnaire form (e.g., magazine subscription, interest survey) using short answers and key words"] had been designated a writing item but was categorized as a reading task by both statistical procedures. It is important to note that in order to accomplish this supposed writing task, the student must first read the questionnaire and comprehend what information it seeks. In other words, this language task required a combination of two skills. Someone who is unable to read the questionnaire will obviously be unable to provide written responses to the questions. The students apparently perceived the combination of skills reflected in Item 25 , thus explaining why the cluster and discriminant analyses of the MDS solution "misclassified" the item. Thus, the results from the MDS solution combined with those from the cluster and discriminant analyses provided strong evidence that the four skills structure specified in the test blueprint was also evident in the student response data.

\section{SME Response Data}

MDS solutions. The two- and three-dimensional solutions from the SME response data were rejected because of STRESS values above .10 and RSQ values below .90 (Table 1), and because the addition of a fourth dimension was interpretable. Because the fifth dimension was not interpretable, that solution was rejected.

After the decision had been made to retain four dimensions for the SME data (Dimensions R1, R2, $R 3$, and $R 4$ ), the four raters were asked what criteria they used in performing the ratings. This informal check on the solution corroborated the results and is discussed below.

Selected plots that facilitate interpretation of the four-dimensional solution are provided in Figure 2. Figure 2 a shows a clear separation along Dimension $\mathbb{R} l$ of the receptive (listening and reading) and productive (speaking and writing) skills. The listening and reading items are located in the left half of the plot, and the speaking and writing items cluster in the right half. Dimension $R 2$ separated the two receptive skills-the listening items are toward the top and the reading items are toward the bottom.

In Figure $2 \mathrm{~b}$, Dimension $\mathbb{R} 3$ tends to distinguish the productive skills. The speaking items tend to be located in a region above the writing items.

Figure 2c shows Dimension R4, which was interpreted as item difficulty. Item 29 ( ${ }^{6}$ Write a term paper on a topic I have researched") is a language task that would be very difficult for the learners involved in the present study and thus is at the top of the plot. Items 2, 5, and 30 are located toward the bottom of the plot. These items [e.g., Item 5: "Talk about my daily routine (e.g., when I get up, when I go to the university or work, etc. $\left.)^{9}\right]$ represent language tasks that novice learners can be expected to accomplish to some degree.

The informal check with the raters after the dimensions had been extracted and interpreted confirmed the interpretation of Dimension $\mathbb{R} 4$ as language task difficulty. All raters stated that task difficulty was indeed a criterion they used in performing the dissimilarity judgments. In addition, the scale values of Dimension $R 4$ from the SME configuration were correlated with Dimension $R 1$ from the student response data (interpreted as task difficulty) and with the Likert-scale item means. The correlations were -.56 and highly significant (directionality is not of consequence). In short, although language task difficulty was not one of the primary criteria used by the raters in comparing the items, the raters perceived the difficulty of the items as did the students.

Cluster and discriminant analysis. As for the student data, both cluster analysis and predictive discriminant analyses produced the same results: all items but one (Item 30) were classified into the four language skill areas as specified in the original test blueprint. Item 30 ('Respond to an invitation to visit someone, either accepting or declining") was designed to be a writing item but was misclassified as a speaking item. On closer examination of the wording of Item 30, however, the potential for misclassification becomes clear. An invitation can be "responded" to either verbally or in writing.

Thus, the raters provided strong evidence that their 


\section{APPLED PSYCHOLOGICAL MEASUREMENT}

Figure 2

Stimulus Configurations of the Four-Dimensional Solution From the SME Data

a. Item Classifications for Dimensions $\mathrm{R} 1$ and $\mathrm{R} 2$

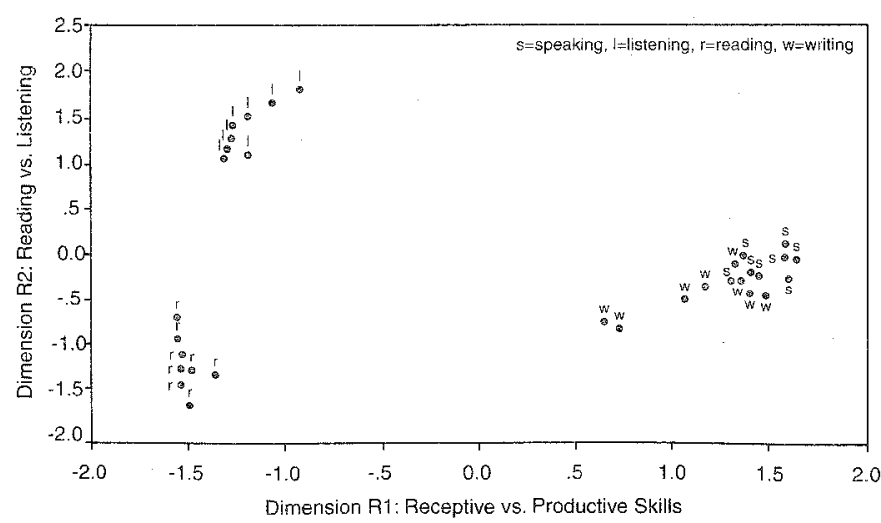

b. Item Classifications for Dimensions $\mathbb{R} 2$ and $\mathbb{R} 3$

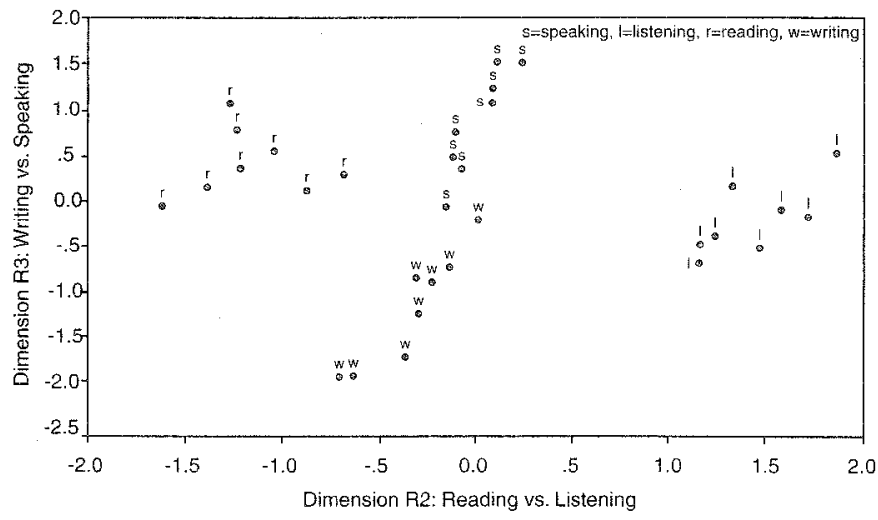

c. Item Numbers for Dimensions $\mathbb{R} 1$ and $R 4$

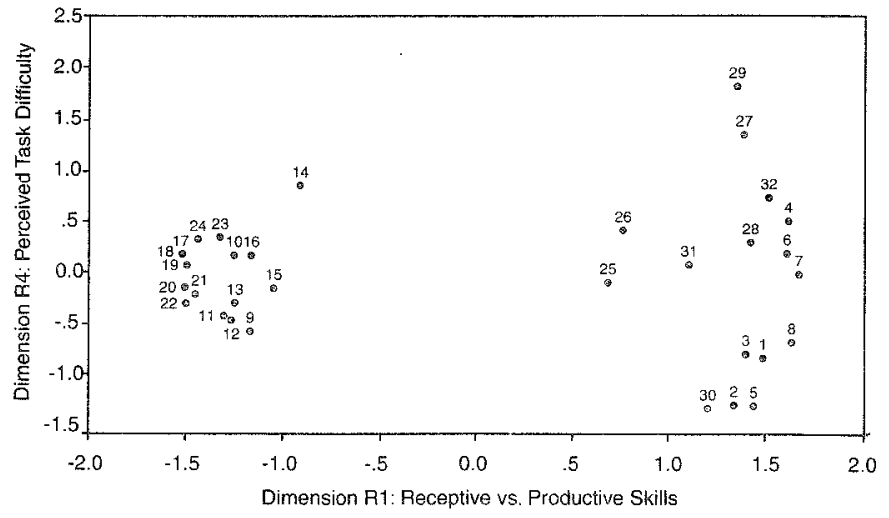

Downloaded from the Digital Conservancy at the University of Minnesota, http://purl.umn.edu/93227. May be reproduced with no cost by students and faculty for academic use. Non-academic reproduction requires payment of royalties through the Copyright Clearance Center, http://www.copyright.com/ 
perceptions of the content structure of the SA items were very similar to the structure oullined in the test blueprint. Interestingly, the analyses of the student response data revealed one misclassified item (Item 25), and the analyses of the SME data also indicated one misfitting item (Item 30). The misfit of both deviant items was easily interpretable and pointed to the fact that there was some overlap of skills required to complete given language tasks.

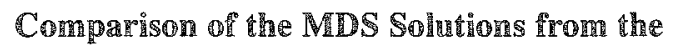

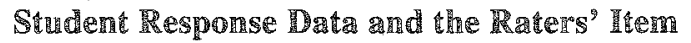

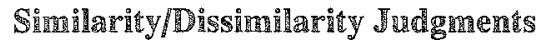

There are several confirmatory techniques available to researchers comparing MDS solutions (Heiser \& Meulman, 1983; Young \& Hamer, 1987). Canonical correlation, a technique recommended by several authors to compare MDS or FA solutions (Heiser \& Meulman, 1983; Levine, 1977) and used by Schiffman, Reynolds, \& Young (1981), was used here. Canonical correlation is an appropriate tech nique in the present research context for two reasons: the two solutions are independent, and a simple transformation of one spatial configuration cannot be expected to reproduce the other.

Table 2 shows the results of the canonical correlation analysis. The analysis was performed by using the four-dimensional stimulus coordinates for the 32 items from the student response data as one set of variables, and the four-dimensional stimulus coordinates for the items from the raters' data as the second set of variables.

The canonical correlations for the four variates ranged from $R=.95$ to $R=.38$. The significance level of the first three variates was at the .0001 probability level (Wilks' Lambda $=.004, .048$, and .332 , respectively). The fourth variate was statistically significant at the .04 probability level.

The squared canonical correlations $\left(R^{2}\right)$ ranged from .91 to .15 and indicate the proportion of variance of the linear composites explained by the correlation. The relatively high values for the first three variates suggest that these variates were most helpful in understanding the relationship among the two sets of variables.

Interpretation of canonical regression is not without controversy (Thompson, 1984). The consensus, however, is that the structure coefficients provide the most meaningful information for interpretation (Pedhazur, 1982; Tatsuoka, 1988; Thompson, 1984). Structure coefficients represent the bivariate correlations between the original variables and the variates, and are sometimes referred to as loadings.

Table 3 shows that the structure coefficients with the highest loadings were on the first canonical variate. These coefficients were RI and S3 (.91 and .82, respectively), and corresponded to the first dimension from the raters' data and the third dimension from the student response data. Recall that these dimensions from the two MDS solutions were interpreted as distinguishing the receptive and productive language skills. The first canonical variate, then, can be interpreted as the distinction between listening and reading tasks (receptive skills) and speaking and writing tasks (productive skills).

The highest loadings on the second variate were R2 (.87) and $\$ 2(.78)$, and represented the second dimensions from the raters' and students' solutions. Dimension $\mathrm{R} 2$ was interpreted as the separation of the listening and reading skills. Dimension 52 was explicated as being the distinction between the communication (speaking and listening) and literacy

Tabie 2

Canonical Correlations $\left(R_{c}\right)$, Eigenvalues, Proportion of the Sum of the Eigenvalues, Wilks' Lambda, and $F$ Tests for Student and SME MDS Solutions

\begin{tabular}{|c|c|c|c|c|c|c|c|c|c|}
\hline \multirow[b]{2}{*}{$\begin{array}{c}\text { Canonical } \\
\text { Variate }\end{array}$} & \multirow[b]{2}{*}{$R_{c}$} & \multirow[b]{2}{*}{$R_{c}^{2}$} & \multirow[b]{2}{*}{$\begin{array}{l}\text { Eigen- } \\
\text { value }\end{array}$} & \multirow[b]{2}{*}{$\begin{array}{l}\text { Pro- } \\
\text { portion }\end{array}$} & \multirow[b]{2}{*}{$\begin{array}{c}\text { Wilks' } \\
\text { Lambda }\end{array}$} & \multicolumn{4}{|c|}{ Degrees of Freedom } \\
\hline & & & & & & $F$ & $\begin{array}{l}\text { Numer- } \\
\text { ator }\end{array}$ & $\begin{array}{l}\text { Denomi- } \\
\text { nator }\end{array}$ & $p$ \\
\hline 1 & .95 & $\frac{c}{91}$ & 10.34 & .57 & .004 & 23.12 & 16 & 74 & .0001 \\
\hline 2 & .93 & .86 & 5.98 & .33 & .048 & 16.92 & 9 & 61 & .0001 \\
\hline 3 & .78 & .61 & 1.57 & .09 & .332 & 9.56 & 4 & 52 & .0001 \\
\hline 4 & .38 & .01 & .17 & .01 & .855 & 4.59 & 1 & 27 & .0413 \\
\hline
\end{tabular}




\section{Volume 20 Number 2 June 1996
136 APPLIED PSYCHOLOGICAL MEASUREMENT}

Trbie 3

Canonical Structure Coefficients

\begin{tabular}{crrrr}
\hline & \multicolumn{4}{c}{ Canonical Variate } \\
\cline { 2 - 5 } Dimension & \multicolumn{1}{c}{1} & \multicolumn{1}{c}{2} & \multicolumn{1}{c}{3} & 4 \\
\hline R1 & .91 & .11 & -.14 & .37 \\
R2 & -.31 & .87 & .03 & .38 \\
R3 & .28 & .37 & .51 & -.72 \\
R4 & -.08 & -.30 & .82 & .48 \\
S1 & .07 & -.22 & -.97 & .02 \\
S2 & .59 & .78 & -.13 & -.17 \\
S3 & .82 & -.54 & .18 & .03 \\
S4 & .14 & .12 & -.01 & .98 \\
\hline
\end{tabular}

(reading and writing) skills, of which listening and reading were a subset. Thus, the second canonical variate can be interpreted as the differentiation between the communication and literacy skills, with an emphasis on the separation of listening and reading.

The third canonical variate had high structure coefficients representing item difficulty. Dimensions R4 (.82) and S1 $(-.97)$ were the two dimensions from the raters' and students' solutions that were interpreted as language task difficulty.

The last canonical variate was significant at the .04 probability level. The strongest loading on this variate belonged to $\$ 4(.98)$, the fourth dimension of the students' solution that was interpreted as the amount of structure required by the language task. The next highest loading was on $R 3(-.72)$, the separation of speaking and writing skills, but the other three raters' dimensions had loadings above 30 on the fourth canonical variate. The fourth canonical variate was not clearly interpretable, but as Tatsuoka (1988) stated, empirical evidence of association between two domains may not always be interpretable but may be important for subsequent research.

The redundancy coefricient, $R_{d}$ (Stewart \& Love, 1968 ), is an asymmetric index of common variance in a canonical correlation analysis that is often reported. $R_{d}$ should be interpreted with caution (Cramer \& Nicewander, 1979; Thompson, 1984) and only as a summary index. $R_{d}$ can be thought of as "...an index of the average proportion of variance in the variables that is reproducible from the variables in the other set" (Thompson, 1984, p. 25). In the present study, $R_{d(\mathrm{R} . \mathrm{S})}$, or the proportion of variance in the SME solution accounted for by (or in common with) the student response solution, was $.68 . R_{d(S R)}$, the proportion of the variance in the student response solution explained by the SME solution, was .65 . These values are relatively high and indicate a strong association between the dimensions in the fwo MDS sollutions. Thus, the components and/or structure underlying the two solutions exhibited a strong association that corresponded to the test content specified in the blueprint for the SA items.

\section{Discussion}

This study used information from three sourcestest/item specifications, SMEs' judgments of items, and actual student responses-to investigate the hypothesized structure underlying the items. Expert judgments from SMEs typically are used in the test construction stage, a process that is usually considered as part of "content validity." Analyzing the structure of test items is most often undertaken after the administration of the test in order to confirm or reject the postulated structure, and factor analysis is the preferred technique. Investigators often speak of "construct validity" when performing such procedures. The present study combined the two approaches and presented a strategy to examine validity using both content and construct information.

Two issues, practical and conceptual in nature, need to be considered at this point. In practice, asking SMES to perform item dissimilarity comparisons can be a lengthy, tedious, and unwieldy task. The SMEs in this study had to make 496 paired comparisons for the 32 items. Obviously, more itens will increase the number of paired comparisons exponentially. With a large number of items, the demand on the raters could render the technique unworkable. In high-stakes testing situations, consideration of SME work load may have to be sacrificed in order to insure the validity of a test's content. Additionally, considerable work has been undertaken by Spence (1982, 1983) that can guide researchers in designing and collecting incomplete data models for use in MDS. Spence (1982) pointed out, however, that using incomplete experimental designs may not even be necessary. He demonstrated that the use of a random subset of item pairs can pro- 
duce surprisingly stable and similar results to those from the complete design.

The relatively small number of SMES used in this study was suitable to demonstrate the technique. If, however, the assessment context were high-stakes, additional SMEs would provide greater confidence in the stability and generalizability of the rating results.

The validation technique proposed in this study is not likely to produce favorable results when the conceptualized content structure lacks explicitness and specificity. This limitation, however, applies not only to the present technique but to any validation procedure. If the boundaries of the content domain can be specified clearly and unambiguously, and if items can be written to represent the nonoverlapping content areas, then validation research will have more power to uncover the underlying structures.

However, when content areas are ambiguous and overlap, neither SME nor examinee data can be expected to reveal the hypothesized content structure. When a lack of convergent evidence ensues from the procedures, the researcher must investigate the potential problem sources. Several weak items, as found in the present study, are perhaps the most innocuous threat to validity. A lack of agreement among the validity sources could call into question not only the operationalization of the construct, but the theory underlying it as well.

The present study has important implications for both psychometricians and test practitioners. Psychometricians have long called for an empirical technique that links information from SMES and test responses with regard to test content. The methodology presented here accomplishes this unification of important validity information. The technique is labor intensive, and may be especially useful in a high-stakes assessment situation. Practitioners musi learn to gather multiple sources of validity information in order to evaluate their testing practices. Although an investment of effort is needed to implement the validation technique proposed here, the costs for not properly validating assessment procedures may be higher.

\section{References}

Aldenderfer, M. S., \& Blashfield, R. K. (1984). Cluster analysis. Newbury Park CA: Sage.

Arabie, P., Carroll, J. D., \& DeSarbo, W. J. (1987). Threeway scaling and clustering. Newbury Park CA: Sage.

Bachman, L. F. (1990). Fundamental considerations in language testing. Oxford: Oxford University Press.

Bachman, L. F., \& Palmer, A. S. (1981). The construct validity of the FSI oral interview. Language Leaming, 31, 67-86.

Bachman, L. F., \& Palmer, A. S. (1982). The construct validity of some components of communicative proficiency. TESOL Quarterly, 16, 449-465.

Barrows, T., Ager, S. M., Bennett, M. F., Braun, H. I. Clark, J. D. L., Harris, L. G., \& Klein, S. F. (1981). College siudents' knowledge and beliefs: A survey of global undersianding. New Rochelle NY: Change Magazine Press.

Birckbichler, D. W., Corl, K. A., \& Deville, C. W. (1993). The dynamics of placement testing: Implications for articulation and program revision. In D. P. Benseler (Ed.), The dynamics of language program direcion (pp. 155-171). Boston: Heinle \& Heinle.

Cramer, E. M., \& Nicewander, W. A. (1979). Some symmetric, invariant measures of multivariate association. Psychometrika, 44, 43-54.

Crocker, L. M., Miller, D., \& Franks, E. A. (1989). Quantitative methods for assessing the fir between test and curriculum. Applied Measurenent in Education, 2, 179-194.

Cronbach, L. J. (1971). Test validation. In R. L. Thorndike (Ed.), Educational measurement (2nd ed.; pp. 443-507). Washington DC: American Council on Education.

Cronbach, L. J., \& Meehl, P. E. (1955). Construct validity in psychological tests. Psychological Bulletin, 52 , 281-302.

Davidson, $\mathbb{F}_{0}$ \& Henning, G. A. (1985). A self-rating scale of English difficulty: Rasch scalar analysis of items and rating categories. Language Testing, 2, $164-179$.

Davison, M. L. (1985). Multidimensional scaling versus components analysis of test intercorrelations. Psychological Bulletin, 97, 94-105.

Davison, M. L. (1992), Multidimensional scaling (2nd ed.). Malabar FL: Krieger.

Davison, M. L., \& Srichantra, N. (1988). Acquiescence in components analysis and multidimensional scaling of self rating items. Applied Psychological Measurement, 12, 339-351.

Ebel, R. L. (1977). Comments on some problems of employment testing. Personnel Psychology, 30, 55-63.

Fitzpatrick, A.R. (1983). The meaning of content validity. Applied Psychological Measurement, 7, 3-13. 
Guion, R. M. (1977). Content validity: The source of my discontent. Applied Psychological Measurement, 1, $1-10$.

Gulliksen, H. (1950). Intrinsic validity. American Psychologist, 5, 511-517.

Heilenman, L. K. (1990). Self-assessment of second language ability: The role of response effects. Language Testing, 7, 174-201.

Heilenman, L. K. (1991). Self-assessment and placement: A review of the issues. In $\mathbb{R}$. V. Teschner (Ed.), Issues in language program direction: Assessing foreign language proficiency of undergraduates (pp. 93-114). Boston: Heinle \& Heinle.

Heiser, W. J., \& Meulman, J. (1983). Constrained multidimensional scaling, including confirmation. Applied Psychological Measurement, 7, 381-404.

Kane, M. (1994). Validating the performance standards associated with passing scores. Review of Educational Research, 64, 425-461.

Kruskal, J. B., \& Wish, M. (1978). Multidimensional scaling. Beverly Hills: Sage.

LeBlanc, R., \& Painchaud, G. (1985). Self-assessment as a second language placement instrument. TESOL Quarterly, 19, 673-687.

Levine, M. S. (1977). Canonical analysis and factor comparison. Beverly Hills: Sage.

Likert, R. (1974). A method of constructing an attitude scale. In G. M. Maranell (Ed.), Scaling: A sourcebook for behavioral scientists (pp. 233-243). Chicago: Aldine.

Messick, S. (1975). The standard problem: Meaning and values in measurement and evaluation. American Psychologist, 30, 955-966.

Messick, S. (1989a). Meaning and values in test validation: The science and ethics of assessment. Educational Researcher, 18, 5-11.

Messick, S. (1989b). Validity. In R. L. Linn (Ed.), Educational measurement (3rd ed.; pp. 13-103). New York: American Council on Education.

Milligan, G. W., \& Cooper, M. C. (1987). Methodology review: Clustering methods. Applied Psychological Measurement, 11, 329-354.

Moss, P. A. (1995). Themes and variations in validity theory. Educational Measurement: Issues and Practice, 14(2), 5-13.

Napior, D. (1972). Nonmetric multidimensional techniques for summated ratings. In $R$. N. Shepard, A. $\mathbb{K}$. Romney, \& S. B. Nerlove (Eds.), Multidimensional scaling: Theory and applications in the behavioral sciences. Volume I: Theory (pp. 157-178). New York: Seminar Press.

Oltman, P. K., Stricker, L. I., \& Barrows, T. S. (1990), Analyzing test structure by multidimensional scaling. Journal of Applied Psychology, 75, 21-27.

Oskarsson, M. (1989). Self-assessment of language pro- ficiency: Rationale and applications. Language Testing, $6,1-13$.

Osterlind, S. J. (1989). Constructing test items. Hingham MA: Kluwer-Nijhoff.

Pedhazur, E. J. (1982). Multiple regression in behavioral research: Explanation and prediction ( 2 nd ed.). New York: Holt, Rinehart and Winston.

Reilly, R.R., \& Warech, M. A. (1991). The validity and faimess of alternatives to cognitive tests. Unpublished manuscript, AT\&T.

Ross, $\mathbb{R}$. T. (1934). Optimal orders in the method of paired comparisons. Joumal of Experimental Psychology, 25, $414-424$.

Schiffman, S. S., Reynolds, M. L., \& Young, F. W. (1981). Introduction to multidimensional scaling. Orlando FL: Academic Press.

Shepard, L. A. (1993). Evaluating test validity. In L. Darling-Hammond (Ed.), Review of research in education, 19 (pp. 405-450). Washington DC: American Educational Research Association.

Sireci, S. G. (1995, April). The central role of content representation in test validity. Paper presented at the annual meeting of the American Educational Research Association, San Francisco.

Sireci, S. G., \& Geisinger, K. F. (1992). Analyzing test content using cluster analysis and multidimensional scaling. Applied Psychological Measurement, 16, $17-31$.

Sireci, S. G., \& Geisinger, $\mathbb{K}$. G. (1995). Using subject matter experts to assess content representation: $A$ MDS analysis. Applied Psychological Measurement, 19, 241-255.

Spector, P. E. (1992). Summated rating scale construction: An introduction. Newbury Park CA: Sage.

Spence, 1. (1982). Incomplete experimental designs for multidimensional scaling. In $\mathbb{R}$. G. Golledge \& $\mathbb{I}$. N. Rayner (Eds.), Proximity and preference: Problems in the multidimensional analysis of large data sets (pp. 29-46). Minneapolis: University of Minnesota Press.

Spence, I. (1983). Monte carlo simulation studies. Applied Psychological Measurement, 7, 405-425.

Stewart, D. K., \& Love, W. A. (1968). A general canonical correlation index. Psychological Bulletin, 70, $160-163$.

Tatsuoka, M. M. (1988). Multivariate analysis: Techniques for educational and psychological research (2nd ed.). New York: Macmillan.

Tenopyr, M. L. (1977). Content-construct confusion. Personnel Psychology, 30, 47-54.

Thompson, B. (1984). Canonical correlation analysis: Uses and interpretation. Beverly Hills CA: Sage.

Thorndike, R. L. (1982). Applied psychometrics. Boston: Houghton-Mifflin.

Tucker, L. T. (1961, November). Factor analysis of relevance judgments: An approach to content validity. 
Paper presented at the Invitational Conference on Testing Problems, Princeton NI. $\mathbb{N}$ Reprinted in A. Anastasi (Ed.), Testing problems in perspective, 1966 , (pp. 577-586). Washington DC: American Council on Education.]

von Elek, T. (1985). A test of Swedish as a second language: An experiment in self-assessment. In Y. Lee, A. Fok, R. Lord, \& G. Low (Eds.), New directions in language testing (pp. 47-57). Oxford: Oxford University Press.

Williams, L. J., Cote, J. A., \& Buckley, M. R. (1989). Lack of method variance in self-reported affect and perceptions at work: Reality or artifact? Journal of Applied Psychology, 74, 462-468.

Yalow, E. S., \& Popham, W. J. (1983). Content validity at the crossroads. Educational Researcher, 12(8), $10-14,21$

Young, F. W., \& Hamer, R. M. (1987). Multidimensional scaling: History, theory, and applications. Hillsdale
NJ: Erlbaum.

Young, F. W., \& Harris, D. F. (1990). Multidimensional scaling: Procedure ALSCAL. In SPSS Inc, SPSS base system user's guide (pp. 397-505). Chicago: SPSS, Inc.

\section{Aclenow}

This research was supported in part by a grant from the Fund for the Improvement of Postsecondary Education. A previous version of this paper was presented at the Annual Meeting of the American Educational Research Association, April, 1994. The paper benefited from the insightful comments and suggestions of Susan Brookhart, Stephen Sireci, the editor, and two anonymous reviewers.

\section{A}

Send requests for reprints or further information to Craig W. Deville, Sylvan Prometric, 2601 W. 88th Street, Bloomington MN 55431, U.S.A. Email: cdeville@ prometric.com.

Downloaded from the Digital Conservancy at the University of Minnesota, http://purl.umn.edu/93227.

May be reproduced with no cost by students and faculty for academic use. Non-academic reproduction requires payment of royalties through the Copyright Clearance Center, http://www.copyright.com/ 